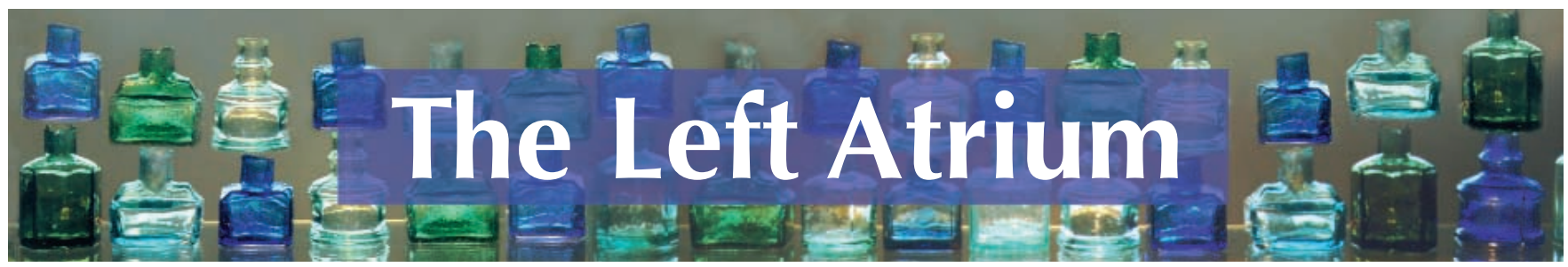

\section{Coming home to mindfulness in medicine}

Coming to our senses

Jon Kabat-Zinn

New York: Hyperion; 2005

631 pp \$21.95 (paper) ISBN 0-7868-8654-4

We shall not cease from exploration

And the end of all our exploring

Will be to arrive where we started

And know the place for the first time.

— T.S. Eliot, "Little Gidding," 1942

Creat. But don't dismiss it too

Tquickly. I think Eliot is talking about something that is relevant to healing in the practice of medicine and to the book being reviewed here. Let me start with my experience. When I switched from nephrology to palliative care three years ago, I noticed something unusual when I talked with patients who were dying. Of course, in 24 years of practising nephrology I had cared for many patients who eventually died and had even looked after some of them up to the moment of death. But this was different. In the context of palliative care I experienced a sense of peace, a freedom from hurry and a heightened interest in and awareness of the patient as a person. This was new to me in a medical context. Time seemed to slow down, and the possibilities of the moment expanded exponentially. Speaking with a patient whom I acknowledged was dying expanded my awareness - or, in the words of philosopher Jacob Needleman, captured the full force of my attention:

This force of attention appears when through a great shock or a situation of total urgency, all the routine functions of the whole human mind release the higher energies held captive by them.

I felt more fully myself than ever before in my medical practice.

If I had read Jon Kabat-Zinn and his latest book, Coming to Our Senses, I would have called this experience "mindfulness." He writes:

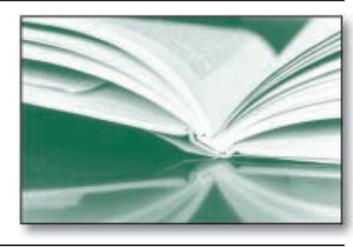

Mindfulness can be thought of as momentto-moment, non-judgmental awareness, cultivated by paying attention in a specific way, that is, in the present moment, and as non-reactively, as non-judgmentally, as openheartedly as possible.

His wonderful book is a thorough exploration of mindfulness and how it can be cultivated, and of the implications of such a development for healing ourselves and others.

Cultivating mindfulness is, on the face of it, a simple business: one may meditate in one of the many ways outlined by Kabat-Zinn in his book or by other writers on meditation. But for that to work you must first understand what meditation is really about. I used to think it was a calming kind of exercise in which you repeated a word or paid attention to your breathing and fell into a pleasant trance. I used to think along the same lines about golf before I played the game. In fact, meditation is like a kind of mental golf in which the aim is moment-tomoment attention to the process at hand. This attention involves letting go of attachment to the past moment and of interest in the next. Like playing golf without getting preoccupied with the previous shot or the next one, this is easier said than done. But if we care enough and practise diligently we learn to loosen our attachment to ordinary distractions and to "fall awake" to ourselves.

What does this have to do with the

practice of medicine? One day, circa 1910, Sir William Osler was on his way to present degrees at Oxford, dressed in the full regalia of the Regius Professor of Medicine. He was asked to see a young boy apparently dying of whooping cough. Here is a description of the encounter by a brother of the patient:

The Regius, about to present for degrees and hard pressed for time, arrived already wearing his doctor's robes ... . To a small child this was the advent of a doctor, if doctor it in fact was, from quite a different planet. It was more probably Father Christmas.

After a very brief examination this unusual visitor sat down, peeled a peach, sugared it and cut it in pieces. He then presented it bit by bit with a fork to the entranced patient, telling him to

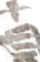


described by Eric Cassell in The Healer's Art (1976) and further developed by Michael Kearney in A Place of Healing (2000). Curing is an eradication or a change in the disease state induced primarily by the physician's exertions. Healing is a response shift in the person healed toward a sense of integrity and wholeness. The energy for healing comes from the patient, although the process may be facilitated by a deep and supportive relationship with a health care worker. Stimulated in part by the success of alternative medical practitioners, physicians are beginning to rediscover healing as an important part of what society wants from them. The challenge is that the qualities required for curing and healing are different and even contradictory. For instance, as Cassell has written, in the curing mode the physician focuses on what the patient shares in common with other patients with the same disease, while in the healing mode he or she pays attention to the unique characteristics and context of the patient. But can a normal person pay attention in two contradictory ways at the same time? Are we asking too much of physicians and other health care workers?

I suspect that we are not asking enough. I believe that most health care workers are capable of being fully present to their patients as professionals and as whole human beings. For myself I realize in retrospect that is why I got into medicine in the first place. And, surprisingly, living in accordance with our real and often challenging values may be less stressful than the alternative. ${ }^{3}$ I agree with Kabat-Zinn that techniques for cultivating mindfulness are central to this deeper interpretation of the health care mandate. But there is probably more to it than simply learning a technique. Buddha, the originator of mindfulness, gave up all of his material possessions and took to the road with his begging bowl. Our shaman precursors went through a near-death experience or psychotic episode before they were qualified for practice. What is the equivalent for 21 st-century physicians? Perhaps it is a question that each physician needs to ask himself or herself: What do you need to give up, or what commitment do you need to make to bring the full force of your attention to the practice of medicine? And maybe healing is a question that physicians need to explore for themselves and for their patients: What would it take for you to come home to yourself? This, I believe, is the arrival T.S. Eliot was talk- ing about. Never left? Are you sure?

\section{Tom A. Hutchinson}

Director, McGill Programs

in Whole Person Care

Department of Oncology

McGill University

Montréal, Que.

\section{References}

1. Needleman J. The way of the physician. London: Arkana; 1985.

2. Bliss M. William Osler: a life in medicine. Toronto: University of Toronto Press; 1999. p. 374.

3. Massimini F, Delle Fave A. Individual development in a bio-cultural perspective. Am Psycho 2000;55:24-33.

\section{From prose into practice}

$T$ he mindfulness meditation workshop with Dr. Jon Kabat-Zinn is scheduled to run for three hours. The afternoon begins with a 20-minute guided meditation, followed by a question-and-comment session with the workshop's 250 participants. One hour into the afternoon's activities I realize there's very little new here. I'm almost ready to cut it short and begin my two-hour drive home.

We are mostly patients and former patients of the Tom Baker Cancer Centre in Calgary. Women in the audience outnumber men about eight to one. One middle-aged woman gratefully testifies to the power of meditation in helping her confront her breast cancer. A man asks Jon if he ever falls asleep while meditating.

Our speaker admits that he does get sleepy from time to time while sitting in meditation. He reminds us that, contrary to popular misconception, mindfulness meditation is not about achieving bliss or states of extraordinary calm or enlightenment. It's more about the simple, mundane struggle to remain awake in the present moment. Simple does not imply easy. Jon acknowledges real difficulties in being continually mindful. A woman in her fifties admits that she finds less time for meditation now that the crisis of cancer in her life has receded.

Be alive in the present moment. That exhortation is a recurring theme in Jon's writing. Was I expecting something more from the man himself? Surely this task by itself is sufficient for one workshop, if not for one lifetime. I make a mental note of my impatience and set it gently aside. As Jon says, the workshop is today's meditation. He then leads us in some quiet yoga stretching, followed by another short period of silent meditation. The final 30 minutes is devoted to more "conversation" between Jon and the participants.

Jon indicates he'll stay to answer any additional queries and also sign copies of his books. As I gather up my things and anticipate the late afternoon traffic, the title of his second book comes to mind: Wherever You Go, There You Are.

\section{Vincent Hanlon}

Emergency Physician

Lethbridge, Alta. 